R. Casasola, J.M. Pérez, M. Romero, Devitrification behavior and preferred crystallization mechanism of glasses based on fluorrichterite $\left(\mathrm{Na}_{2} \mathrm{CaMg}_{5} \mathrm{Si}_{8} \mathrm{O}_{22} \mathrm{~F}_{2}\right)$ composition.

\title{
Devitrification behavior and preferred crystallization mechanism of glasses based on fluorrichterite $\left(\mathrm{Na}_{2} \mathrm{CaMg}_{5} \mathrm{Si}_{8} \mathrm{O}_{22} \mathrm{~F}_{2}\right)$ composition
}

\author{
R. Casasola, J.M. Pérez, M. Romero*
}

Group of Glass and Ceramic Materials, Instituto de Ciencias de la Construcción Eduardo Torroja, CSIC. C/ Serrano Galvache 4. 28033 Madrid. Spain.

\footnotetext{
* Corresponding author, Tel.: +34 9130204 40; Fax: + 34913020700.

e-mail address: mromero@ietcc.csic.es
}

\begin{abstract}
This paper reports on the effect of different contents of fluorine on the thermal stability of glasses in the $\mathrm{SiO}_{2}-\mathrm{MgO}-\mathrm{CaO}-\mathrm{Na}_{2} \mathrm{O}-\mathrm{F}$ system. Four glass compositions, with experimental fluorine contents varying from 2.12 to 4.39 wt. $\%$, were studied using differential scanning calorimetry (DSC). The devitrification behavior was assessed through the evaluation of both the glass stability (GS) and glass-forming ability (GFA) using different parameters calculated from the characteristic temperatures in non-isothermal DSC curves. The predominant crystallization mechanism was determined by the difference in the crystallization temperature $\left(\Delta \mathrm{T}_{\mathrm{p}}\right)$ between fine and coarse glass samples. The results indicate that the studied melts exhibit a low tendency to devitrify during cooling, although this trend is increased with the fluorine content. The glass thermal stability is affected by the particle size, with it being easier to crystallize a glass powder sample than a coarse glass sample. The surface crystallization mechanism is predominant at the beginning of the devitrification process; however, the volume crystallization acquires importance with an increase in the fluorine content.
\end{abstract}

Keywords: F-richterite; glass-forming ability; glass stability parameters; crystallization mechanism; DSC; oxyfluoride glasses.

\section{Introduction}

Generically, glasses can be defined as substances that have certain characteristics of solids, such as mechanical hardness and brittleness at room temperature, but that cannot be considered strictly as solids because they lack the characteristic crystalline structure of the solid state. [1].

Glass devitrification to develop a glass-ceramic material proceeds through a thermal process that usually occurs in two steps, nucleation (small seeds or nuclei emerge within the glass) and 
R. Casasola, J.M. Pérez, M. Romero, Devitrification behavior and preferred crystallization mechanism of glasses based on fluorrichterite $\left(\mathrm{Na}_{2} \mathrm{CaMg}_{5} \mathrm{Si}_{8} \mathrm{O}_{22} \mathrm{~F}_{2}\right)$ composition.

crystal growth (the enlargement of crystals is facilitated). In turn, the nucleation of crystalline phases can occur through two different mechanisms, i.e., homogeneous nucleation, when the nuclei arise from their own melt composition in the absence of foreign boundaries, and heterogeneous nucleation, when crystalline phases develop from foreign boundaries, such as grain borders or interfaces [2].

Glass-ceramics have been shown to feature excellent thermal, chemical, biological and dielectric properties, which are due, in great extent, to the nature of the crystalline phases developed upon heating. Fluorrichterite (hereafter, F-richterite) is an amphibole with empirical formula $\mathrm{Na}_{2} \mathrm{CaMg}_{5} \mathrm{Si}_{8} \mathrm{O}_{22} \mathrm{~F}_{2}$. Glass-ceramics based on F-richterite are of great technological interest because of their excellent mechanical properties, chemical durability and crack propagation resistance. Hence, K-F-richterite glass-ceramics are used in the manufacture of hard drives [3] or high-quality tableware [4].

Another field in which F-richterite plays an important role is in dental restoration. Frichterite glass-ceramics are machinable and exhibit high strength and toughness, excellent acid and alkali chemical durability, and remarkable resistance to slow crack growth [4]. Denry and Holloway highlighted that these glass-ceramics were potential candidates as high-strength dental ceramics $[5,6,7]$.

However, although F-richterite glass-ceramics have been demonstrated to exhibit promising properties, little is known regarding the ability of F-richterite-based melts to develop amorphous glasses and on the preferential crystallization mechanism that governs the devitrification of Frichterite glasses.

Differential scanning calorimetry (DSC) has proven to be a suitable technique to evaluate the main parameters required to understand both the glass stability and glass crystallization behavior [8-17]. The aim of the present paper was to study the effect of fluorine content on the glass-forming ability, glass stability and preferred crystallization mechanism of a series of glasses based on F-richterite composition $\left(\mathrm{Na}_{2} \mathrm{CaMg}_{5} \mathrm{Si}_{8} \mathrm{O}_{22} \mathrm{~F}_{2}\right)$.

\section{Theory}

In general, when a glass is subjected to a thermal treatment, devitrification takes place because of the energy decrease that occurs when the structurally amorphous glass crystallizes and results in a solid phase with a regular ordered geometry [18]. The glass stability (GS) indicates the strength of a glass against the nucleation and growth of crystalline phases during 
R. Casasola, J.M. Pérez, M. Romero, Devitrification behavior and preferred crystallization mechanism of glasses based on fluorrichterite $\left(\mathrm{Na}_{2} \mathrm{CaMg}_{5} \mathrm{Si}_{8} \mathrm{O}_{22} \mathrm{~F}_{2}\right)$ composition.

thermal treatment. The GS of glasses can be easily evaluated from different parameters calculated from the characteristic temperatures in a DSC curve, including the glass transition temperature $\left(T_{g}\right)$, onset crystallization temperature $\left(T_{x}\right)$, peak crystallization temperature $\left(T_{p}\right)$ and melting temperature $\left(T_{m}\right)$ considered as the temperature at the minimum of the first endothermic peak.

Depending on the location where the first crystals form, the devitrification of a glass upon heating above Tg can evolve by two different mechanisms, volume and surface crystallization. In volume or bulk crystallization, crystals are regularly dispersed throughout the internal volume of the glass. However, in surface crystallization, crystals are first nucleated at the glass surface and subsequently extend inwards. In the early stages of devitrification, the positions in which the crystals are located can be evaluated by the difference between the crystallization temperatures of fine (powder) and coarse (bulk) glass samples, $\Delta \mathrm{T}_{\mathrm{p}}[18]$, as follows:

$$
\Delta \mathrm{T}_{\mathrm{p}}=\mathrm{T}_{\mathrm{p} \text { (powder) }}-\mathrm{T}_{\mathrm{p} \text { (coarse) }} .
$$

Thus, $\Delta \mathrm{T}_{\mathrm{p}}>0$ indicates that the first crystals will develop at the surface of the glass particles, whereas if $\Delta \mathrm{T}_{\mathrm{p}}<0$, the devitrification of the glass will begin with the development of nuclei in the internal volume of the glass. GS can also be evaluated based on other parameters, such as the following:

- Reduced glass transition temperature $\mathrm{T}_{\mathrm{gr}}[19]$,

$$
T_{g r}=\frac{T_{g}}{T_{m}}
$$

- Working range $\Delta \mathrm{T}_{\mathrm{TS}}[20]$,

$$
\Delta \mathrm{T}_{\mathrm{TS}}=\mathrm{T}_{\mathrm{x}}-\mathrm{T}_{\mathrm{g}}
$$

- Weinberg $\left(\mathrm{K}_{\mathrm{W}}\right)$ [21], Hrubÿ $\left(\mathrm{K}_{\mathrm{H}}\right)$ [22] and Lu-Liu [23, 24] parameters:

$$
\begin{gathered}
K_{w}=\frac{T_{x}-T_{g}}{T_{m}} \\
K_{H}=\frac{T_{x}-T_{g}}{T_{m}-T_{x}} \\
K_{L L}=\frac{T_{x}}{T_{g}+T_{m}} .
\end{gathered}
$$

The capability of a melt to form a glass while quenched is designated its glass-forming ability (GFA). This ability can be assessed based on the critical cooling rate $\mathrm{q}_{\mathrm{c}}$, which is the minimum cooling rate from melting to $\mathrm{T}_{\mathrm{g}}$ required to avoid crystal formation. This critical 
R. Casasola, J.M. Pérez, M. Romero, Devitrification behavior and preferred crystallization mechanism of glasses based on fluorrichterite $\left(\mathrm{Na}_{2} \mathrm{CaMg}_{5} \mathrm{Si}_{8} \mathrm{O}_{22} \mathrm{~F}_{2}\right)$ composition.

cooling rate can be determined from the Weinberg, Hrubÿ and Lu-Liu parameters using the following equations [25]:

$$
\begin{aligned}
& \log _{10} q_{W}=4.44-21.4 \cdot K_{W} \\
& \log _{10} q_{H}=3.17-2.26 \cdot K_{H} \\
& \log _{10} q_{L L}=17.7-34.6 \cdot K_{L L} .
\end{aligned}
$$

The use of $T_{p}$ instead of $T_{x}$ to determine the $K_{W}, K_{H}$ and $K_{L L}$ parameters used in the $q_{c}$ calculation should noted, according to Nascimento et al. [25, 26].

\section{Materials and methods}

Four glasses in the $\mathrm{SiO}_{2}-\mathrm{MgO}-\mathrm{CaO}-\mathrm{Na}_{2} \mathrm{O}-\mathrm{F}$ system were formulated from high-quality reagents $\left(\left(\mathrm{MgCO}_{3}\right)_{4} \mathrm{Mg}(\mathrm{OH})_{2} \cdot 5 \mathrm{H}_{2} \mathrm{O}, \mathrm{CaCO}_{3}, \mathrm{Na}_{2} \mathrm{CO}_{3}\right.$ and $\left.\mathrm{MgF}_{2}\right)$ and silica sand with low contents of iron oxide. The designated RE composition was prepared with the stoichiometric composition of F-richterite, $\mathrm{Na}_{2} \mathrm{CaMg}_{5} \mathrm{Si}_{8} \mathrm{O}_{22} \mathrm{~F}_{2}$. Moreover, three additional mixtures containing increased amounts of fluorine $(6,8$ and 10 wt. \%) were referred to as R6, R8 and R10, respectively.

The raw material mixtures were homogenized in a planetary ball mill (TURBULA) for 15 min. The batches were melted in alumina-silica crucibles in an electric furnace at a heating rate of $10^{\circ} \mathrm{C} / \mathrm{min}$ up to $1450^{\circ} \mathrm{C}$ and held at that temperature for $120 \mathrm{~min}$ for homogenization. Subsequently, the melts were cooled down to room temperature following two different cooling steps. Thus, frit glasses were achieved through a fast-cooling stage by pouring the melts into cool water. Meanwhile, the bulk glass samples were obtained by casting the melt onto brass molds followed by subsequent annealing for $2 \mathrm{~h}$ at $100^{\circ} \mathrm{C}$ below their respective glass transition temperatures ( $\mathrm{Tg}$ ). After annealing, the glasses were cooled to room temperature inside the furnace. Differential scanning calorimetry (DSC) analyses were conducted previously on the glass samples with the same composition to determine the Tg value for each glass.

The chemical composition of the glasses was determined by X-ray fluorescence (XRF) from pressed pellets of powder glass samples $(<63 \mu \mathrm{m})$ using a BRUCKER S8 Tiger spectrometer. The glass transition temperature ( $\mathrm{Tg}$ ), onset crystallization temperature ( $\mathrm{Tx})$, maximum crystallization peak temperature (Tp) and melting temperature $(\mathrm{Tm})$ were evaluated by DSC on both fine ( $<63 \mu \mathrm{m}$ powder) and coarse ( $\sim 3 \times 3 \times 4 \mathrm{~mm}$ coarse) samples. The DSC runs were performed in a SETARAM Labsys Thermal Analyzer. The samples were heated from room temperature to $1400^{\circ} \mathrm{C}$ at a heating rate of $50^{\circ} \mathrm{C} \cdot \mathrm{min}^{-1}$ under flowing air. Samples of $\sim 40 \mathrm{mg}$ 
R. Casasola, J.M. Pérez, M. Romero, Devitrification behavior and preferred crystallization mechanism of glasses based on fluorrichterite $\left(\mathrm{Na}_{2} \mathrm{CaMg}_{5} \mathrm{Si}_{8} \mathrm{O}_{22} \mathrm{~F}_{2}\right)$ composition.

were placed in platinum crucibles, and calcined $\mathrm{Al}_{2} \mathrm{O}_{3}$ was used as the reference material. All the DSC curves were normalized with respect to the sample weight. The temperature precision of the equipment is $\pm 0.1^{\circ} \mathrm{C}$. Each measurement was reproduced three times to estimate the experimental errors.

The effect of the fluorine content on the GFA of the glasses studied in the present work was corroborated by in situ DSC examinations that replicated the melting program applied in the preparation of these glasses. For this purpose, a mix of raw materials of each glass composition was heated in the DSC equipment from ambient to $1450^{\circ} \mathrm{C}$, applying a heating rate of 50 ${ }^{\circ} \mathrm{C} / \mathrm{min}$. The melt was held at the melting temperature for $30 \mathrm{~min}$, and afterwards, the samples were cooled to room temperature at a rate of $50^{\circ} \mathrm{C} / \mathrm{min}$. Right away, the samples were subjected to a new heating process at $50^{\circ} \mathrm{C} / \mathrm{min}$ up to $1450^{\circ} \mathrm{C}$. Hence, the GFA of the melts can be evaluated from DSC curves recorded during the first cooling step, and the GS of the glasses can be determined from the DSC curves recorded during the second heating ramp.

To ascertain the crystalline phases developed upon cooling, a batch of each glass composition was melted in an electric furnace under the same schedule followed for the in situ DSC runs. To facilitate the development of crystalline phases, the melts were cooled at $50^{\circ} \mathrm{C} / \mathrm{min}$ from $1450^{\circ} \mathrm{C}$ to the temperature of their maximum exothermic effect of the in situ DSC curves recorded during the first cooling step and then held for $30 \mathrm{~min}$. Afterwards, the samples were extracted from the kiln and cooled in air.

The evaluation of the amorphous nature of the as-melted glasses and the mineralogical study of the crystalline phases devitrified after thermal treatment was achieved using X-ray diffraction (XRD) using BRUKER D8 Advance equipment with Ni-filtered $\mathrm{Cu} \mathrm{K} \alpha$ radiation operating at $30 \mathrm{~mA}$ and $40 \mathrm{kV}$. Data were recorded in the 5-60 $2 \theta$ range (step size $0.019732^{\circ}$ and $0.5 \mathrm{~s}$ counting time for each step).

To confirm the effect of fluorine on the preferential crystallization mechanism, samples of glass frit of the different compositions were subjected to a heat treatment at $850^{\circ} \mathrm{C}$ for 10 minutes to support the formation of crystals within the glass. The microstructure of the resulting glass-ceramic materials was studied by field-emission scanning electron microscopy (FESEM) with a HITACHI S-4800P microscope using an acceleration voltage of $20 \mathrm{kV}$. Glass-ceramic samples were polished to a $1 \mu \mathrm{m}$ finish using diamond pastes after initially grinding with $\mathrm{SiC}$ powder. The samples were subsequently etched for $10 \mathrm{~s}$ in a solution of $5 \% \mathrm{HF}$, ultrasonically washed with distilled water and ethylic alcohol, dried and coated with Au-Pd in a Balzers SCD 050 sputter. 
R. Casasola, J.M. Pérez, M. Romero, Devitrification behavior and preferred crystallization mechanism of glasses based on fluorrichterite $\left(\mathrm{Na}_{2} \mathrm{CaMg}_{5} \mathrm{Si}_{8} \mathrm{O}_{22} \mathrm{~F}_{2}\right)$ composition.

\section{Results and Discussion}

After the cooling of the melts, the glasses obtained by both frit and bulk form appeared homogeneous to the naked eye; XRD analysis confirmed their glassy nature.

Table 1 presents the theoretical and experimental chemical analysis results determined by XRF of the parent glasses. In all the analyzed compositions, the following effects were observed: the silica content is slightly increased; alumina is observed in the experimental compositions although it had not been considered in the glass formulations as richterite lacks $\mathrm{Al}_{2} \mathrm{O}_{3}$ in its composition; and a considerable decrease in the percentage of fluorine and sodium oxide is also observed. These results are attributed to the joint effect of the corrosion of the inner surface of the Si-Al crucibles by the melted glass [27] and the fluorine volatilization in the form of $\mathrm{SiF}_{4}$ and $\mathrm{NaF}$ [28]. It is observed that the higher the initial fluorine content in the mixture, the greater the proportion in which the fluorine evaporates from the melt. Similar results have been reported in the literature in fluoride glasses belonging to the $\mathrm{SiO}_{2}-\mathrm{CaO}-\mathrm{K}_{2} \mathrm{O}-\mathrm{F}$ [13] and $\mathrm{SiO}_{2}-\mathrm{Al}_{2} \mathrm{O}_{3}-\mathrm{MgO}-\mathrm{K}_{2} \mathrm{O}-\mathrm{F}$ [14] systems.

Table 1. Theoretical composition and experimental chemical analysis as determined by FRX method (wt.\%) of the studied glasses.

\begin{tabular}{|c|c|c|c|c|c|c|c|}
\hline & & $\mathbf{S i}_{2} \mathbf{O}$ & $\mathbf{A l}_{2} \mathbf{O}_{3}$ & MgO & $\mathrm{CaO}$ & $\mathrm{Na}_{2} \mathrm{O}$ & $\mathbf{F}_{2}$ \\
\hline \multirow{2}{*}{$\mathbf{R E}$} & Theoretical & 57.35 & 0.00 & 24.03 & 6.69 & 7.40 & 4.53 \\
\hline & Experimental & 57.68 & 5.33 & 20.89 & 7.84 & 6.15 & 2.12 \\
\hline \multirow{2}{*}{ R6 } & Theoretical & 56.46 & 0.00 & 23.66 & 6.59 & 7.28 & 6.00 \\
\hline & Experimental & 57.50 & 6.78 & 20.31 & 7.06 & 5.60 & 2.76 \\
\hline \multirow{2}{*}{ R8 } & Theoretical & 55.26 & 0.00 & 23.16 & 6.45 & 7.13 & 8.00 \\
\hline & Experimental & 55.86 & 7.88 & 19.95 & 6.83 & 5.44 & 4.04 \\
\hline \multirow{2}{*}{ R10 } & Theoretical & 54.06 & 0.00 & 22.66 & 6.31 & 6.97 & 10.00 \\
\hline & Experimental & 55.74 & 8.65 & 19.23 & 6.69 & 5.30 & 4.39 \\
\hline
\end{tabular}

Figure 1 depicts the DSC curves of F-richterite glasses recorded from samples with different particle sizes, i.e., fine ( $<63 \mu \mathrm{m}$ powder $)$ and coarse $(\sim 3 \times 3 \times 4 \mathrm{~mm}$ fragment $)$ extracted from glasses obtained in both bulk and frit form. Regardless of the cooling step followed in the 
R. Casasola, J.M. Pérez, M. Romero, Devitrification behavior and preferred crystallization mechanism of glasses based on fluorrichterite $\left(\mathrm{Na}_{2} \mathrm{CaMg}_{5} \mathrm{Si}_{8} \mathrm{O}_{22} \mathrm{~F}_{2}\right)$ composition.

preparation of the glass and the particle size of the sample, all the DSC curves present an exothermic peak after $\mathrm{T}_{\mathrm{g}}$, which indicates that the investigated glasses are susceptible to crystallization in subsequent heating stages.
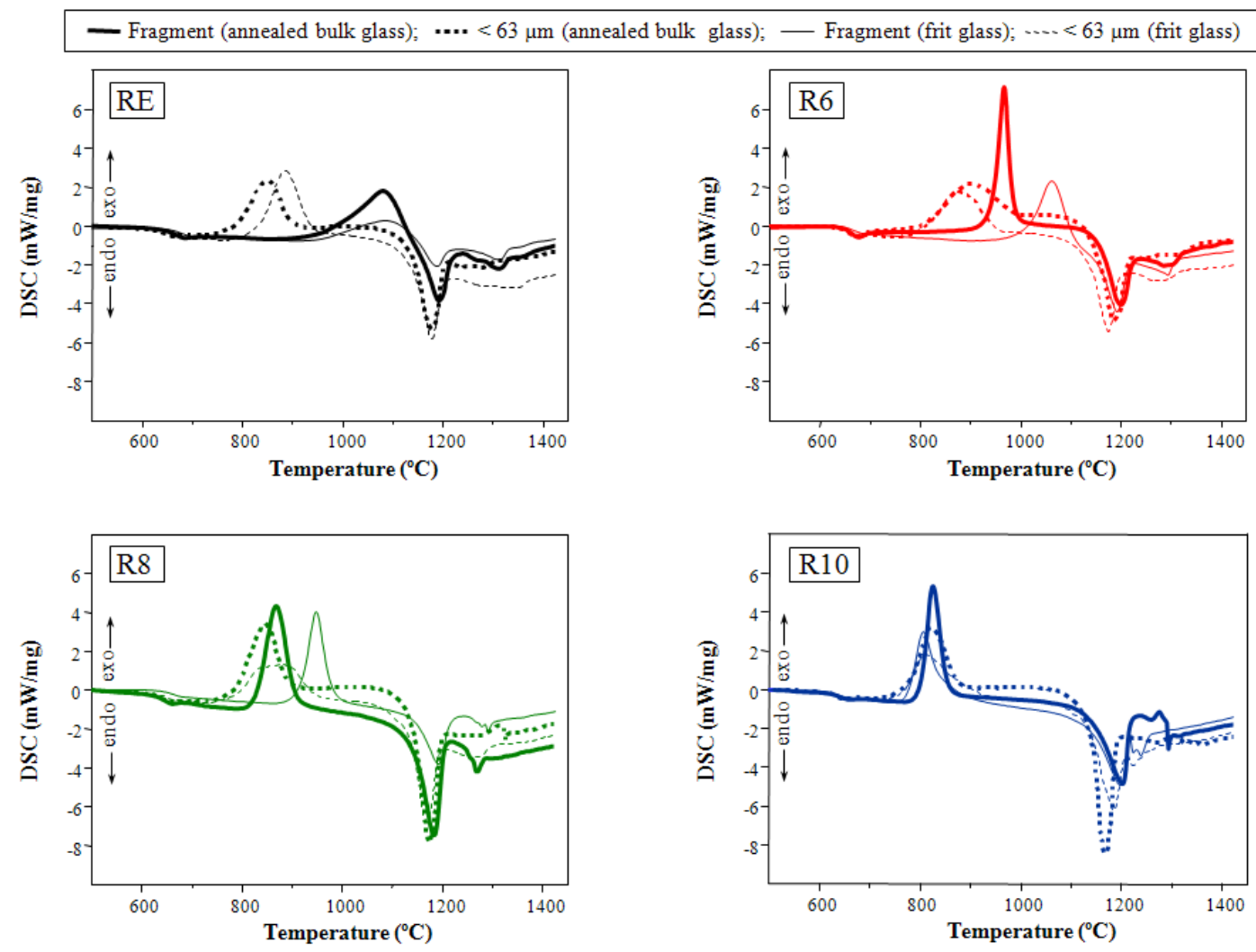

Figure 1. DSC curves from fine $(<63 \mu \mathrm{m})$ and coarse $(\sim 3 \times 3 \times 4 \mathrm{~mm}$ fragment $)$ glass samples recorded at a heating rate of $50{ }^{\circ} \mathrm{C} \cdot \mathrm{min}^{-1}$.

By evaluating both the height and shape of the crystallization peaks, it is observed that the exothermic effects associated with the devitrification of RE glass (Fig. 1a) are relatively wider and less intense than those corresponding to the other glasses. This finding indicates that among the glasses studied, the devitrification of RE glass will result in glass-ceramic materials with a lower crystallinity degree. Regarding the granulometry of the sample, maximum crystallization peaks in RE glass are highly affected by the particle size corresponds to surface crystallization. The more noticeable effect that the fluorine content exerts on the devitrification of F-richterite-based glasses is the enhancement of the volume crystallization with respect to the surface mechanism as the percentage of fluoride in the glass composition increases. Thus, in RE glass, the exothermic peaks corresponding to coarse samples are located at higher temperatures than those in powder samples; however, the difference between the crystallization temperatures 
R. Casasola, J.M. Pérez, M. Romero, Devitrification behavior and preferred crystallization mechanism of glasses based on fluorrichterite $\left(\mathrm{Na}_{2} \mathrm{CaMg}_{5} \mathrm{Si}_{8} \mathrm{O}_{22} \mathrm{~F}_{2}\right)$ composition.

of fine and coarse glass samples decreases with the increasing content of fluorine, such that in R10 glass, all the crystallization exotherms overlap (Fig. 1d). At the same time, the intensities of the exothermic effects in coarse samples are higher than their equivalent of powder samples ( $\mathrm{h}_{\text {bulk fragment }}>\mathrm{h}_{\text {bulk powder }}$ and $\mathrm{h}_{\text {frit fragment }}>\mathrm{h}_{\text {frit powder }}$ ).

Figure 2 plots the characteristic temperatures determined by DSC analyses from fine and coarse samples extracted from glasses prepared in frit and bulk form as a function of the fluorine content in the glass composition. Overall, $\mathrm{T}_{\mathrm{g}}$ and $\mathrm{T}_{\mathrm{m}}$ are characteristic temperatures that exhibit similar values; meanwhile, the variations in $\mathrm{T}_{\mathrm{x}}$ and $\mathrm{T}_{\mathrm{p}}$ are more pronounced. As is usual in fluoride glasses, a higher fluorine content results in decreased $T_{g}$ values (Fig. 2a) due to the fluidizing effect of $\mathrm{F}^{-}$anions $[1,13]$. However, $\mathrm{T}_{\mathrm{g}}$ varies for a given composition depending on the cooling process. Hence, the fast cooling of the melt on water (frit) leads to glasses with higher $\mathrm{T}_{\mathrm{g}}$ values than bulk form glasses, which are subsequently annealed. This result occurs because $\mathrm{T}_{\mathrm{g}}$ is greatly affected by the thermal story of the glass. In quenched glasses, the mobility of the melt constituents is limited by the abrupt increase in viscosity, such that the glass reaches the supercooled liquid state with a more open structure than the glass obtained by casting (slower cooling process), where the increase of viscosity is gradual, and the lattice units take longer to be grouped in a more compact manner [1].

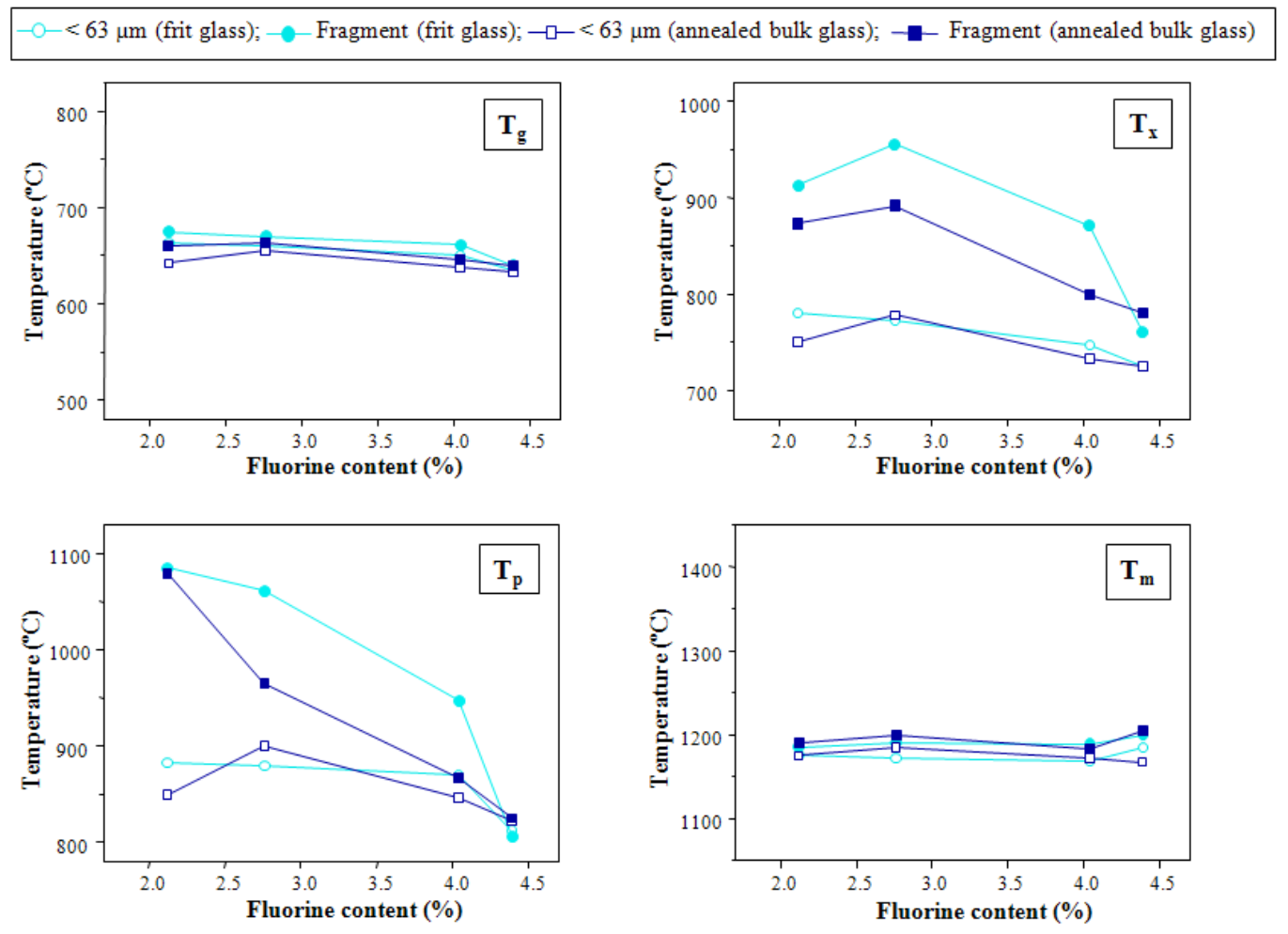

Figure 2. Evolution of the glass transition temperature $\left(\mathrm{T}_{\mathrm{g}}\right)$, onset crystallization temperature $\left(\mathrm{T}_{\mathrm{x}}\right)$, peak crystallization temperature $\left(\mathrm{T}_{\mathrm{p}}\right)$ and melting temperature $\left(\mathrm{T}_{\mathrm{m}}\right)$ with fluorine content. 
R. Casasola, J.M. Pérez, M. Romero, Devitrification behavior and preferred crystallization mechanism of glasses based on fluorrichterite $\left(\mathrm{Na}_{2} \mathrm{CaMg}_{5} \mathrm{Si}_{8} \mathrm{O}_{22} \mathrm{~F}_{2}\right)$ composition.

The fluorine content plays a greater effect on $T_{x}$ (Fig. $2 b$ ) than on $T_{g}$. Thus, while $T_{g}$ varies within a interval of $\sim 40^{\circ} \mathrm{C}$, this gap in $\mathrm{T}_{\mathrm{x}}$ is greater with a difference of $\sim 230^{\circ} \mathrm{C}$ between the minimum and maximum values. The increase in the fluorine content exerts a similar effect on $T_{x}$ as that for $T_{g}$. Therefore, although a slight increase in the values of $T x$ is observed in R6 glass, the general trend for $\mathrm{T}_{\mathrm{x}}$ is to decrease with increasing fluorine concentration in the glass composition. This result indicates that, in general, the increased presence of fluorine in the vitreous network favors the glass devitrification, which begins at lower temperature. Concerning the effect of the thermal history of glass on $T_{x}$, Fig. $2 b$ shows that crystallization in annealed glasses begins at temperatures significantly lower than in fast-cooled glasses, which is more noticeable in coarse samples, although the trend is to converge as the fluorine content increases. Annealed glasses exhibit a more compact and ordered lattice network than frits, and therefore, it is easier to begin the crystallization process. Nevertheless, it appears that the crystallization onset in R10 glass is independent of its thermal history as Tx bulk glass $\sim$ Tx frit glass. This behavior could be associated with the higher fluorine content in its composition. It is known that an elevated fluorine percentage increases the tendency of a melt to crystallize during cooling [13]. The fast quenching of the R10 melt leads to a non-crystalline material, as denoted by its Xray diffraction pattern, typical of amorphous solids. However, molecular aggregates may be formed during fast cooling, which would be in a pre-crystalline state with higher internal order than the glass matrix [1]. This fact would justify the decrease of $T_{x}$ in quenched $R 10$ glass to a value similar to that shown by the annealed glass. Fig. $2 \mathrm{~b}$ also shows the pronounced effect of the glass particle size on the onset crystallization temperature, as $T_{x}$ values are always lower in powder samples. However, $\mathrm{T}_{\mathrm{x}}$ of the bulk glasses considerably decreases upon increasing the fluorine percentage in the glass compositions, such that $\Delta \mathrm{Tx} \sim 120^{\circ} \mathrm{C}$ for RE glass, whereas $\Delta \mathrm{Tx}$ $\sim 40^{\circ} \mathrm{C}$ for $\mathrm{R} 10$ glass. This behavior indicates that crystallization in these glasses preferentially begins at the particles' surface; however, as the fluorine content increases, the formation of crystals in the internal volume of the particles will spread.

Among the different characteristic temperatures, $T_{p}$ is the most affected by the fluorine content in the base glass (Fig. 2c). $T_{p}$ in both fine and coarse samples tends to decrease with increasing fluorine in the composition. However, similar to $T_{x}$, the largest differentiation in $T_{p}$ is observed in coarse samples, with a variation interval of $\sim 280^{\circ} \mathrm{C}$. Figure $2 \mathrm{~d}$ presents the variation of $\mathrm{T}_{\mathrm{m}}$ in the studied glasses. It can be seen that the values of $\mathrm{T}_{\mathrm{m}}$ are very similar (except for R10, which differs from the rest of the samples) which means that both the crystalline and glassy matrix developed are the same for all samples. Thus, even if the crystalline phases would develop in different amounts depending on the fluorine content, the melting would vary a few 
R. Casasola, J.M. Pérez, M. Romero, Devitrification behavior and preferred crystallization mechanism of glasses based on fluorrichterite $\left(\mathrm{Na}_{2} \mathrm{CaMg}_{5} \mathrm{Si}_{8} \mathrm{O}_{22} \mathrm{~F}_{2}\right)$ composition.

degrees. This difference is hardly detected taking the peak temperature. In this way, a variation in this peak temperature would yield differences more noticeable, as it has been mentioned in R10 sample. In powder samples, crystallization occurs at lower temperatures and values of $T_{p}$ seem to be almost independent on the fluorine content of the base glass. This result is likely due to the fact that surface crystallization is initiated at lower energy surface sites. Thus, nuclei formation is almost independent of light fluctuations in the glass composition. $T_{p}$ indicates the temperature at which the crystallization rate is the highest. As the fluorine content in the glass composition increases, the $\mathrm{T}_{\mathrm{p}}$ values for the powder and coarse samples converge. In RE glass with lower fluorine content, the gap in $\mathrm{T}_{\mathrm{p}}$ of samples with different particle sizes implies that for short-time thermal treatment, the crystal growth at the surface of glass particles will be favored over the development of nuclei within the internal volume $\left(T_{p \text { coarse }} \gg T_{p \text { fine }}\right)$. In contrast, in glasses with higher fluorine content (R8, R10), both crystallization mechanisms will occur simultaneously $\left(\mathrm{T}_{\mathrm{p} \text { coarse }} \sim \mathrm{T}_{\mathrm{p} \text { fine }}\right.$ ). This behavior is also supported by $\Delta \mathrm{T}_{\mathrm{p}}$; regardless of the cooling rate used in the preparation of the glass, it varies from $\Delta \mathrm{T}_{\mathrm{p}} \sim-200$ in RE glass to $\Delta \mathrm{T}_{\mathrm{p}} \sim$ 0 in R10 glass.

Figure 3 depicts the values of $\mathrm{T}_{\mathrm{gr}}$ for different glass compositions in coarse and fine $(<63$ $\mu \mathrm{m})$ samples separated from both monolithic and frit glasses. The highlighted region in the diagram distinguishes the prevalence regions of surface and volume crystallization [29, 30, 31]. Fig. 3 shows again a slight predominance of the surface crystallization mechanism because in all cases, $\mathrm{T}_{\mathrm{gr}}$ is greater than 0.60 .

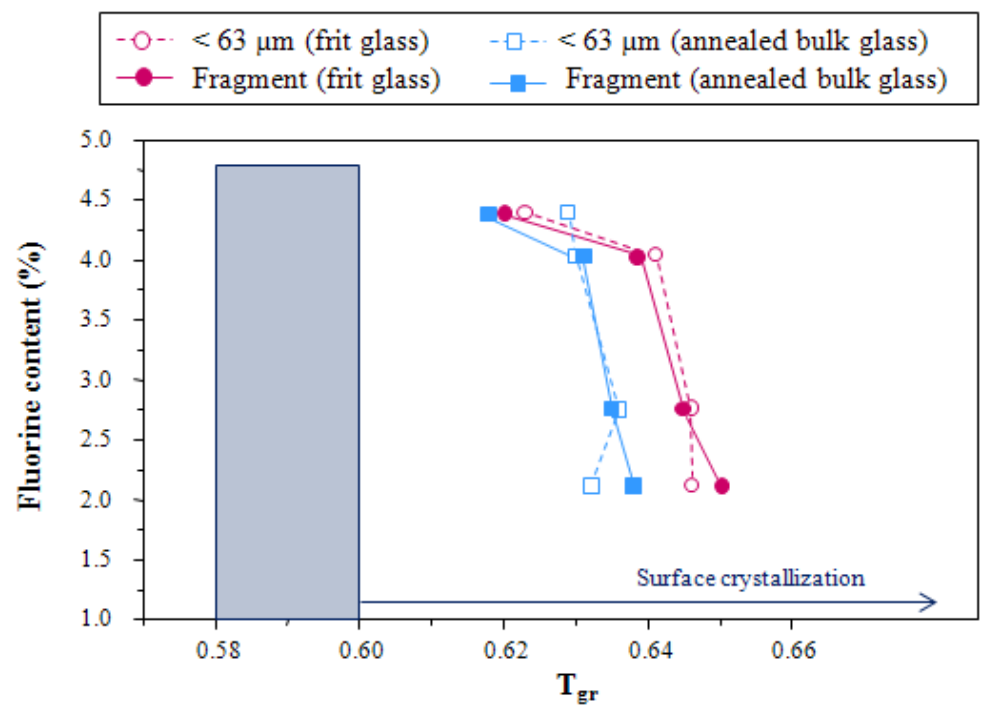

Figure 3. Progress of $\mathrm{T}_{\mathrm{gr}}$ for the different glass compositions in both coarse and fine $(<63 \mu \mathrm{m})$ samples separated from both annealed monolithic and frit glasses. The highlighted region establishes the gap between the surface $\left(\mathrm{T}_{\mathrm{gr}}>0.58-0.60\right)$ and bulk $\left(\mathrm{T}_{\mathrm{gr}}<0.58-0.60\right)$ crystallization. The errors in $\mathrm{T}_{\mathrm{gr}}$ are aprox. $\pm 2-3^{\circ} \mathrm{C}$. 
R. Casasola, J.M. Pérez, M. Romero, Devitrification behavior and preferred crystallization mechanism of glasses based on fluorrichterite $\left(\mathrm{Na}_{2} \mathrm{CaMg}_{5} \mathrm{Si}_{8} \mathrm{O}_{22} \mathrm{~F}_{2}\right)$ composition.

Thermochimica Acta 619 (2015) 32-40; doi:10.1016/j.tca.2015.09.014

To corroborate the preferred crystallization mechanism, coarse samples of annealed glasses were heated for 5 minutes in the range of temperature $850-1000^{\circ} \mathrm{C}$ to induce the development of crystals.

Figure 4 shows the microstructure observed by FESEM in the heat-treated samples. It is apparent that RE glass begins to devitrify through a surface crystallization mechanism, resulting in the development of a crystallization shell in the glass surface. Crystallization in R6 glass is also initiated at the surface of glass particles; however, simultaneously, small spherulitic crystals are developed in the internal body of glass fragments. The crystalline density of spherulitic crystals increases upon increasing the fluorine content in the glass composition (R8 and R10 glasses), which confirms that in the early stages of devitrification of F-richterite-based glasses, crystal growth begins with the development of crystals through a surface crystallization process, and the volume mechanism becomes more important upon increasing the fluorine content in the glass composition.
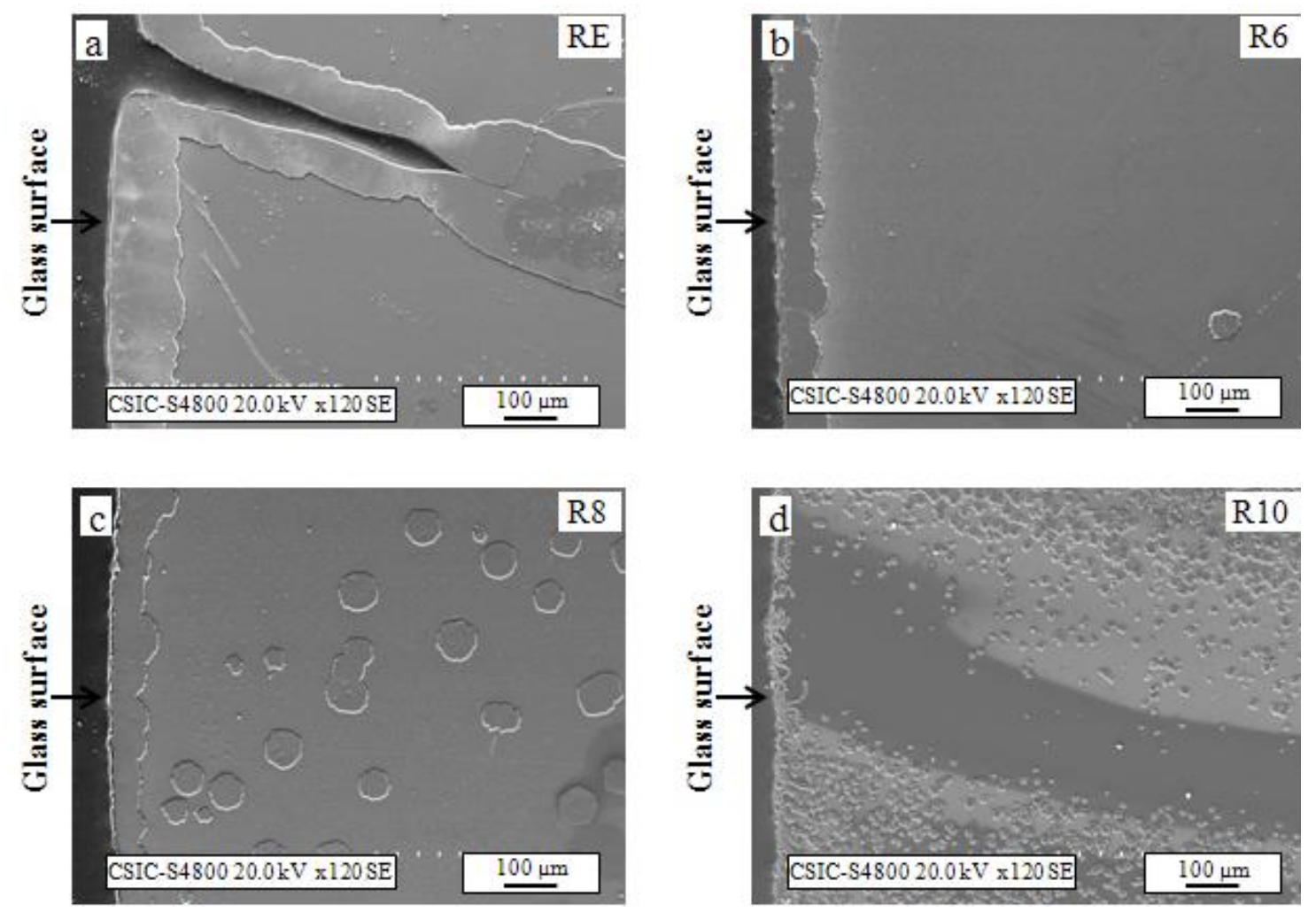

Figure 4. FESEM images of polished and etched surfaces showing the microstructure in the early stages of crystallization of F-richterite-based glasses: a) RE treated at $1000^{\circ} \mathrm{C}$ for $5 \mathrm{~min}$; bR6 treated at $950^{\circ} \mathrm{C}$ for $5 \mathrm{~min}$; c) $\mathrm{R} 8$ treated at $950^{\circ} \mathrm{C}$ for $5 \mathrm{~min}$; and d) $\mathrm{R} 10$ treated at $850^{\circ} \mathrm{C}$ for $5 \mathrm{~min}$. 
R. Casasola, J.M. Pérez, M. Romero, Devitrification behavior and preferred crystallization mechanism of glasses based on fluorrichterite $\left(\mathrm{Na}_{2} \mathrm{CaMg}_{5} \mathrm{Si}_{8} \mathrm{O}_{22} \mathrm{~F}_{2}\right)$ composition.

The thermal stability of the glasses was estimated by calculating both the working range $\left(\Delta \mathrm{T}_{\mathrm{TS}}\right)$ using Eq. (3) and the Hrubÿ $\left(\mathrm{K}_{\mathrm{H}}\right)$, Weinberg $\left(\mathrm{K}_{\mathrm{W}}\right)$ and Lu-Liu parameters $\left(\mathrm{K}_{\mathrm{LL}}\right)$ (Eqs. (4), (5) and (6), respectively).

Figure 5 shows the values of $\Delta \mathrm{T}_{\mathrm{TS}}$ as a function of the fluorine content for different particle size samples of glasses obtained in both annealed and frit form. Smaller values of this temperature interval indicate a lower thermal stability of the glass, and the development of crystalline phases on heating is favored [32]. The $\Delta \mathrm{T}_{\mathrm{TS}}$ values determined from fine samples are, in all cases, inferior to those corresponding to coarse samples. This result indicates that the thermal stability of these glasses is highly affected by the particle size and that fine samples exhibit a greater capability for glass devitrification in subsequent thermal treatments [20]. However, the $\Delta \mathrm{T}_{\mathrm{TS}}$ of fine and coarse samples tend to be equal as the percentage of fluorine in the glass composition increases. This fact indicates that increased fluorine content may involve a variation in the thermal stability of samples with different particle sizes, such that coarse samples become more unstable. Likely, it is due to the ability of fluorine ions to promote bulk nucleation by phase separation, which favors the development of crystalline phases. Indeed, the initiation of phase separation represents the beginning of mica glass-ceramic development in base glasses of the $\mathrm{SiO}_{2}-\mathrm{Al}_{2} \mathrm{O}_{3}-\mathrm{MgO}-\mathrm{Na}_{2} \mathrm{O}-\mathrm{K}_{2} \mathrm{O}$ system [3].

The greater ability of fine glass samples to crystallize is also deducted from Figure 6, in which the Weinberg, Hrubÿ and Lu- Liu parameters are displayed. Lower values of these parameters indicate further ease in obtaining a crystallized material from the parent glass. Regardless of the cooling rate used in the preparation of the glasses, fine samples always exhibit the lowest $\mathrm{K}_{\mathrm{H}}, \mathrm{K}_{\mathrm{W}}$ and $\mathrm{K}_{\mathrm{LL}}$ values, which explain their greater capability to develop crystalline phases upon heating. Figure 6 agrees with Kozmidis -Petrovic [33] showing that $\Delta K_{H}>\Delta K_{W}>$ $\Delta \mathrm{K}_{\mathrm{LL}}\left(\Delta \mathrm{K}=\mathrm{K}_{\text {coarse }}-\mathrm{K}_{\text {fine }}\right)$, so $\mathrm{K}_{\mathrm{LL}}$ can be used as a reference.
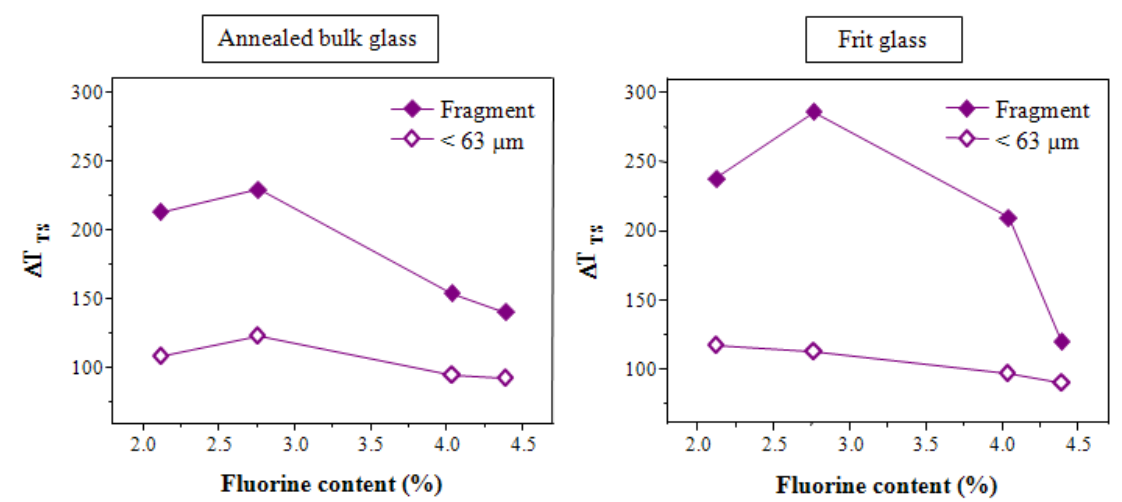

Figure 5. Evolution of $\Delta \mathrm{T}_{\mathrm{TS}}$ with fluorine content for different particle size samples of glasses obtained in both annealed and frit form. The errors in $\Delta \mathrm{T}_{\mathrm{TS}}$ are approximately $\pm 2-3^{\circ} \mathrm{C}$ 
R. Casasola, J.M. Pérez, M. Romero, Devitrification behavior and preferred crystallization mechanism of glasses based on fluorrichterite $\left(\mathrm{Na}_{2} \mathrm{CaMg}_{5} \mathrm{Si}_{8} \mathrm{O}_{22} \mathrm{~F}_{2}\right)$ composition.

$\begin{array}{lll}\rightarrow-\mathrm{K}_{\mathrm{WV}} \text { fragment } & \rightarrow \mathrm{K}_{\mathrm{HI}} \text { fragment } & \rightarrow \mathrm{K}_{\mathrm{LL}} \text { fragment } \\ \rightarrow-\mathrm{K}_{\mathrm{W}}<63 \mu \mathrm{m} & \multimap \mathrm{K}_{\mathrm{H}}<63 \mu \mathrm{m} & \rightarrow-\mathrm{K}_{\mathrm{LL}}<63 \mu \mathrm{m}\end{array}$
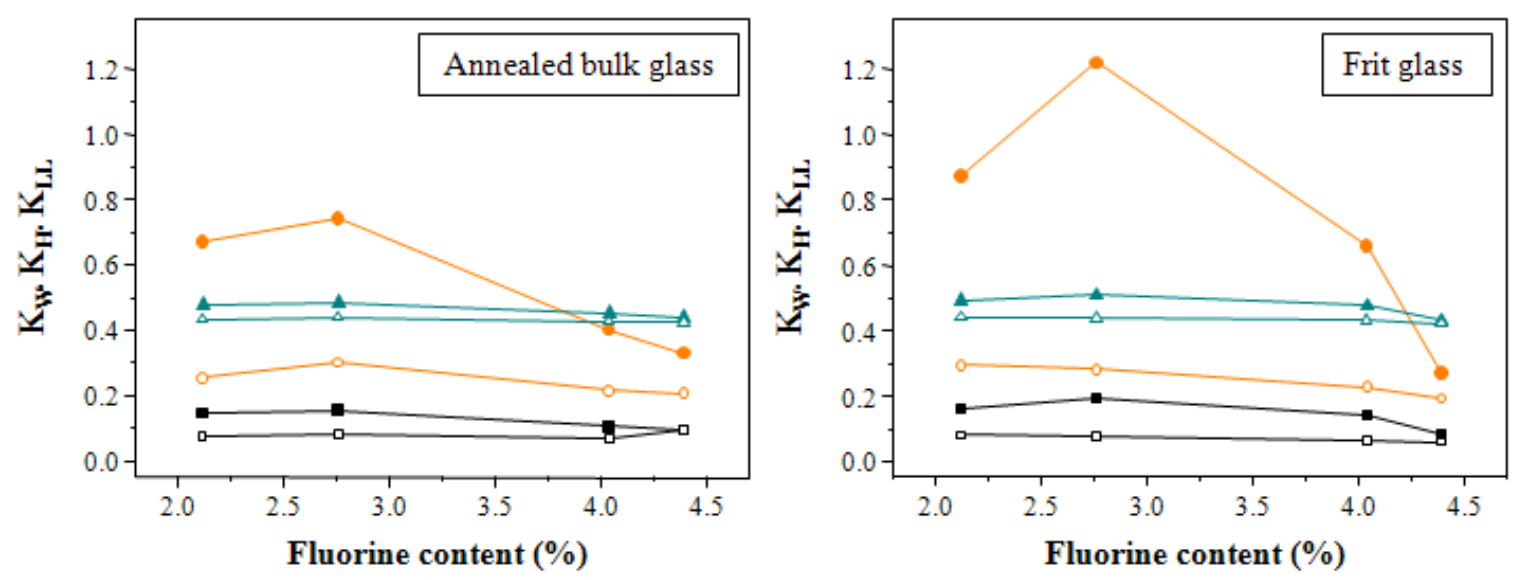

Figure 6. Evolution of Hrüby, Weinberg and Lu-Liu parameters with fluorine content.

Table 2 lists the critical cooling rates of the melts determined from Eq. (7), (8) and (9). These values reveal the GFA of the molten glasses. The studied compositions result in melts with low capacity to crystallize during cooling, except for the R10 melt, which presents critical cooling rates above $65^{\circ} \mathrm{C} / \mathrm{min}$. Therefore, a high fluorine percentage in the raw materials mixture decreases the GFA of the melts.

Table 2. Critical cooling rates for F-richterite based glasses determined from Weinberg, Hrubÿ and LuLiu parameters.

\begin{tabular}{|l|l|l|l|}
\hline & $\mathbf{q}_{\mathbf{W}}\left({ }^{\mathbf{o}} \mathbf{C} / \mathbf{m i n}\right)$ & $\mathbf{q}_{\mathbf{H}}\left({ }^{\mathbf{o}} \mathbf{C} / \mathbf{m i n}\right)$ & $\mathbf{q}_{\mathbf{L L}}\left({ }^{\mathbf{}} \mathbf{C} / \mathbf{m i n}\right)$ \\
\hline $\mathrm{RE}$ & 15 & 29 & 8 \\
$\mathrm{R} 6$ & 15 & 29 & 8 \\
$\mathrm{R} 8$ & 15 & 32 & 9 \\
$\mathrm{R} 10$ & 70 & 125 & 68 \\
\hline
\end{tabular}


R. Casasola, J.M. Pérez, M. Romero, Devitrification behavior and preferred crystallization mechanism of glasses based on fluorrichterite $\left(\mathrm{Na}_{2} \mathrm{CaMg}_{5} \mathrm{Si}_{8} \mathrm{O}_{22} \mathrm{~F}_{2}\right)$ composition.

Figure 7 presents the in situ DSC graphs recorded from raw material mixtures. The curves confirm the effect of the fluorine content on GFA of the melts (Fig. 7a) and the thermal stability of the resulting glasses in a subsequent heating process (Fig. 7b). Table 3 lists the values of the characteristic temperatures determined from the curves in Fig. 7. It is evident that the molten composition resulting from R10 is the only one resulting in the formation of crystalline phases upon cooling, as evidenced by the existence of two exothermic peaks in its corresponding curve (Fig. 7a). This result indicates that the cooling rate $\left(50^{\circ} \mathrm{C} / \mathrm{min}\right)$ is not high enough to avoid crystallization. This behavior is consistent with the critical cooling rates determined for the different glasses (Table 2), where $\mathrm{q}_{\mathrm{c}}<50^{\circ} \mathrm{C} / \mathrm{min}$ for the RE, R6 and R8 compositions, whereas $\mathrm{q}_{\mathrm{c}}>50^{\circ} \mathrm{C} / \mathrm{min}$ for R10. The DSC curves recorded upon heating of RE, R6 and R8 glasses (Fig. $7 b)$ present the typical profile of a glass with a high trend for devitrification. The endothermic jump in the $630-660^{\circ} \mathrm{C}$ range represents the glass transition temperature $\left(T_{g}\right)$, and the exothermic effect at higher temperatures is consistent with a devitrification process. Conversely, the DSC curve corresponding to R10 glass presents neither Tg nor crystallization exothermics, which indicates that the preceding cooling process resulted in a high devitrification degree.
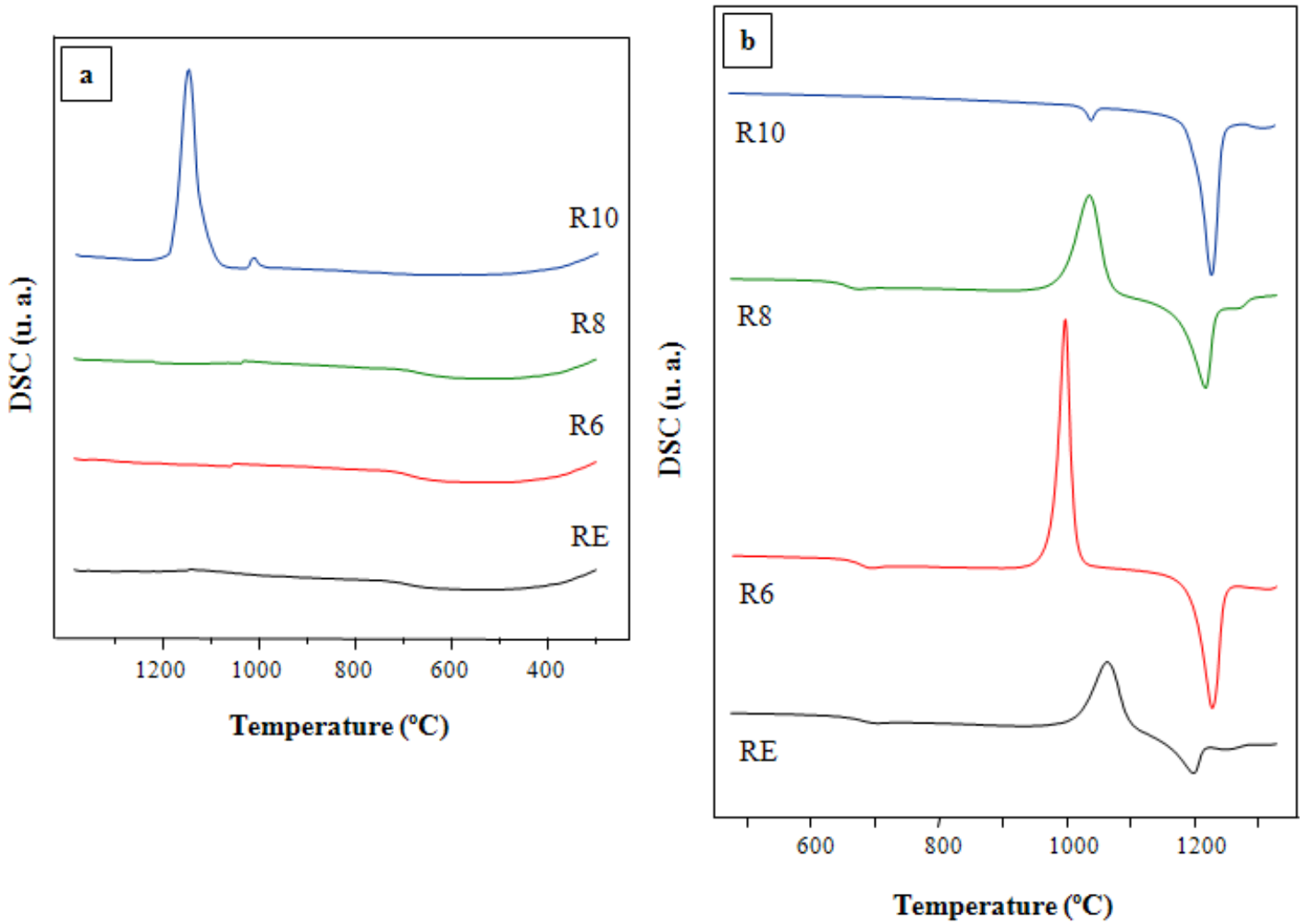

Figure 7. In situ DSC curves recorded from a mixture of raw materials of each glass composition. The batches were up to $1450^{\circ} \mathrm{C}$ and held for $30 \mathrm{~min}$. Subsequently, the melts were cooled to room temperature at $50^{\circ} \mathrm{C} / \mathrm{min}$ (Fig. 7a) and immediately exposed to a re-heating ramp at $50^{\circ} \mathrm{C} / \mathrm{min}$ up to $1450^{\circ} \mathrm{C}$ (Fig. $7 \mathrm{~b}$ ). 
Table 3. Characteristics temperatures derived from DSC curves recorded during a) the cooling step after the melting of raw materials and b) subsequent heating of the resulting material. The errors in the characteristics temperatures are approximately $\pm 2-3^{\circ} \mathrm{C}$.

\begin{tabular}{|c|c|c|c|c|c|}
\hline & \multirow{2}{*}{$\begin{array}{l}\text { Cooling step } \\
\text { (Graph a) in Fig. 7) }\end{array}$} & \multicolumn{4}{|c|}{$\begin{array}{l}\text { Heating } \\
\text { (Graph b) in Fig. 7) }\end{array}$} \\
\hline & & $\mathbf{T}_{\mathrm{g}}\left({ }^{\circ} \mathrm{C}\right)$ & $\mathbf{T}_{\mathbf{x}}\left({ }^{\circ} \mathbf{C}\right)$ & $\mathbf{T}_{\mathbf{p}}\left({ }^{\circ} \mathbf{C}\right)$ & $\mathbf{T}_{\mathrm{m}}\left({ }^{\circ} \mathbf{C}\right)$ \\
\hline $\mathrm{RE}$ & - & 657 & 924 & 1036 & 1171 \\
\hline R6 & - & 652 & 889 & 970 & 1200 \\
\hline $\mathrm{R} 8$ & - & 630 & 896 & 1008 & 1190 \\
\hline R10 & Exothermics at $1150^{\circ} \mathrm{C} ; 1013^{\circ} \mathrm{C}$ & - & - & - & $1013 ; 1202$ \\
\hline
\end{tabular}

The overall analysis of Fig. 7 reveals the antagonist effect of fluorine in glasses. At low concentrations, fluoride ion exerts a fluidizing action and decreases the glass viscosity, as evidenced by the decrease in $\mathrm{T}_{\mathrm{g}}$ with increasing fluorine content (Table 3). However, fluoride ions at higher concentrations increase the molecular mobility in the melt, which favors the reorganization of basic units, resulting in the formation of crystalline phases upon cooling [28].

To identify the crystalline phases devitrified upon cooling of the R10 melt, a mixture of raw materials was subjected to melting at $1450^{\circ} \mathrm{C}$, and afterwards, the melts were cooled at $50^{\circ} \mathrm{C} / \mathrm{min}$ to the temperature corresponding to the two exothermic effects in Fig. $7 \mathrm{~b}\left(1150^{\circ} \mathrm{C}\right.$ and $1013^{\circ} \mathrm{C}$ ). After holding for 30 minutes, to promote the growth of crystalline phases, the samples were removed from the furnace and cooled in air. Figure 8 presents the diffractograms of the resulting materials. As expected, melt crystallization occurred and resulted in glassceramic materials composed of F-richterite (PDF 25-0808) as the main crystalline phase and mica (PDF 25-0155) to a minor extent. The diffractogram corresponding to stopping the cooling at $1150^{\circ} \mathrm{C}$ consists of more intense and better defined peaks and a lower amorphous background. This effect is related to the difference in the intensity of the exothermic peaks in the DSC curves recorded upon melt cooling (Fig. 7a). 
R. Casasola, J.M. Pérez, M. Romero, Devitrification behavior and preferred crystallization mechanism of glasses based on fluorrichterite $\left(\mathrm{Na}_{2} \mathrm{CaMg}_{5} \mathrm{Si}_{8} \mathrm{O}_{22} \mathrm{~F}_{2}\right)$ composition.

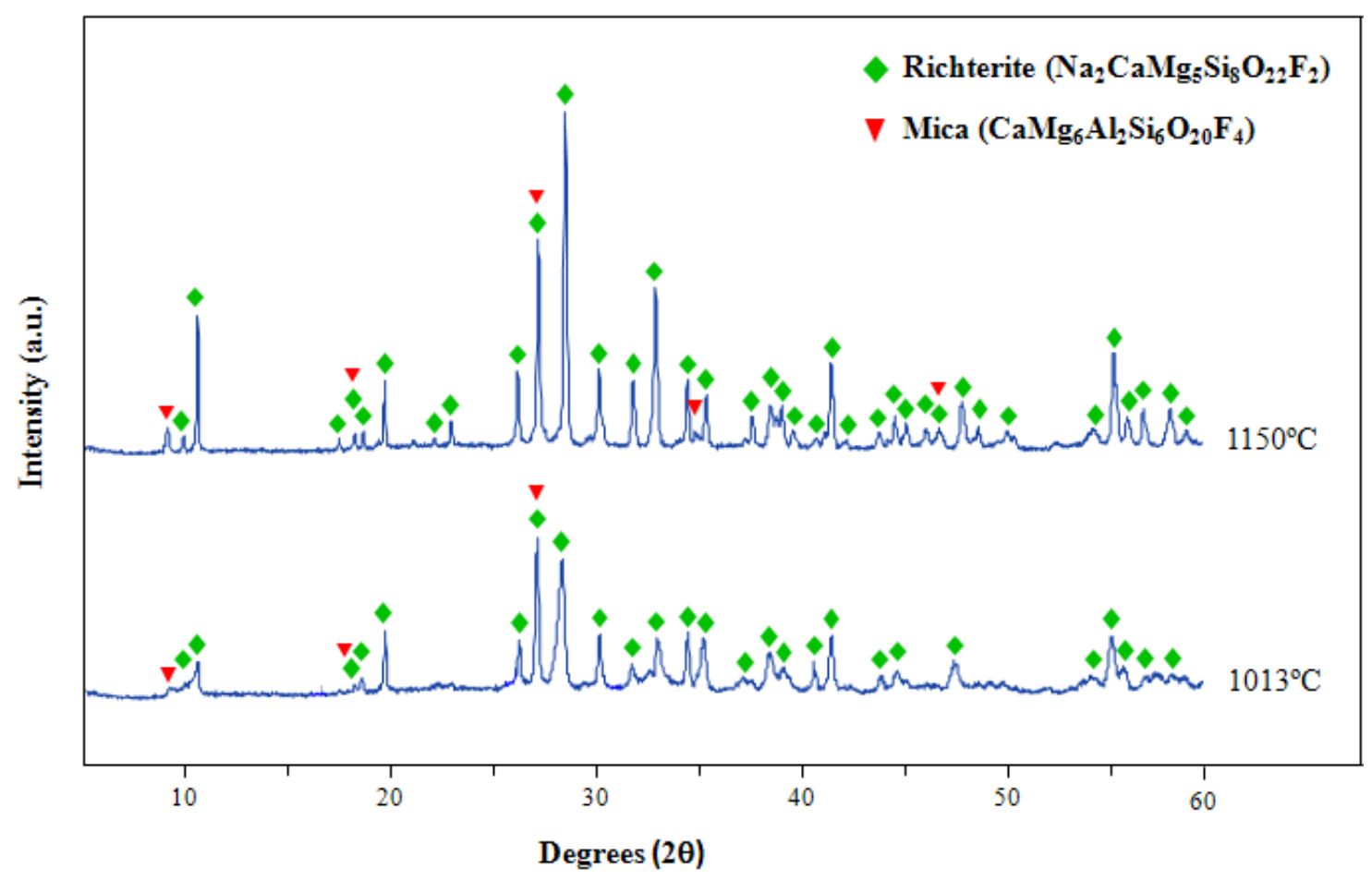

Figure 8. XRD patterns of the glass-ceramic materials resulted after discontinuing the R10 melt cooling for 30 $\mathrm{min}$ at the temperatures of its corresponding exothermic effects in Fig. 7a.

\section{Conclusions}

Four F-richterite-based glasses in the $\mathrm{SiO}_{2}-\mathrm{MgO}-\mathrm{CaO}-\mathrm{Na}_{2} \mathrm{O}-\mathrm{F}$ system were obtained in both frit and annealed form. The glasses were evaluated by DSC to determine the effect of the fluorine content on the glass-forming ability, glass stability and predominant devitrification mechanism of the base glasses. The main conclusions of the present work are as follows:

- The crystallization process of F-richterite glasses proceeds through both surface and volume mechanisms.

- The characteristic temperatures $\left(T_{g}, T_{x}\right.$, and $\left.T_{p}\right)$ decrease upon increasing the fluorine content because of its fluidizing effect.

- The variation of the temperature of crystallization $\left(\Delta \mathrm{T}_{\mathrm{p}}\right)$ with the particle size increases with the fluorine content, varying from $\Delta \mathrm{T}_{\mathrm{p}}<<0\left(\Delta \mathrm{T}_{\mathrm{p}}=\mathrm{T}_{\mathrm{p} \text { fine }}-\mathrm{T}_{\mathrm{p} \text { coarse }}\right)$ in RE glass to $\Delta \mathrm{T}_{\mathrm{p}} \sim 0$ in R10 glass. This tendency indicates a variation in the crystallization mechanism, such that the devitrification process in glasses with low fluorine percentages will begin with the development 
R. Casasola, J.M. Pérez, M. Romero, Devitrification behavior and preferred crystallization mechanism of glasses based on fluorrichterite $\left(\mathrm{Na}_{2} \mathrm{CaMg}_{5} \mathrm{Si}_{8} \mathrm{O}_{22} \mathrm{~F}_{2}\right)$ composition.

of crystals in the surface of the glass particles, whereas the volume crystallization achieves more importance upon increasing the fluorine content.

- The reduced glass transition temperature $\left(\mathrm{T}_{\mathrm{gr}}\right)$ shows a slight predominance of the surface crystallization mechanism at the beginning of the devitrification process because all the glasses present a value of $\mathrm{T}_{\mathrm{gr}}>0.60$.

- The glass thermal stability $\left(\Delta \mathrm{T}_{\mathrm{TS}}\right)$ is affected by the particle size, such that a glass powder sample $(<63 \mu \mathrm{m})$ exhibits a superior ability for glass crystallization.

- The critical cooling rates of the melts are always below $35^{\circ} \mathrm{C} / \mathrm{min}$ for RE, R6 and R8 glasses and above $65^{\circ} \mathrm{C} / \mathrm{min}$ for R10 glass. These values indicate that the raw material mixtures of these compositions yield melts with a low tendency to devitrify during cooling, although this trend is increased with increasing fluorine content in the melt composition.

\section{Acknowledgements}

The authors would like to acknowledge Mrs. P. Díaz for her technical support in the experimental study. R. Casasola and J.M. Pérez express their gratitude to the Spanish National Research Council (CSIC) for their contract through the JAE Program (JAEPre-08-00456 and JAEDoc-08-00362, respectively), which is co-financed by the European Social Fund. The financial support through the projects MAT 2006-05977 and MAT2013-40477-P is also recognized.

\section{References}

[1] J.M. Fernández Navarro, El vidrio, Consejo Superior de Investigaciones Científicas and Sociedad Española de Cerámica y Vidrio, Madrid, 2003.

[2] R. Casasola, J.Ma. Rincón, M. Romero, Glass-ceramic glazes for ceramic tiles-A review, J. Mat. Sci. 47(2) (2012) 553-582.

[3] W. Höland, G. Beall, Glass-ceramic technology, The American Ceramic Society, Westerville, 2002.

[4] G.H. Beall, Chain silicate glass-ceramics, J. Non-Cryst. Solids. 129 (1991) 163-173.

[5] I.L. Denry, J.A. Holloway, Effect of magnesium content on the microstructure and crystalline phases of fluoramphibole glass-ceramics, J. Biomed. Mater. Res. (Appl. Biomater.) 53 (2000) 289-296.

[6] I.L. Denry, J.A. Holloway, Effect of Sodium Content on the Crystallization Behavior of Fluoramphibole Glass-Ceramics, J. Biomed. Mater. Res. (Appl. Biomater.) 63 (2002) 48-52. 
R. Casasola, J.M. Pérez, M. Romero, Devitrification behavior and preferred crystallization mechanism of glasses based on fluorrichterite $\left(\mathrm{Na}_{2} \mathrm{CaMg}_{5} \mathrm{Si}_{8} \mathrm{O}_{22} \mathrm{~F}_{2}\right)$ composition.

Thermochimica Acta 619 (2015) 32-40; doi:10.1016/j.tca.2015.09.014

[7] I.L. Denry, J.A. Holloway, Elastic constants, Vickers hardness, and fracture toughness of fluorrichterite-based glass-ceramics dental materials, Dent. Mater. 20 (2004) 213-219.

[8] A.F. Kozmidis-Petrovic, Which glass stability criterion is the best? Thermochim. Acta 523 (2011) 116-123.

[9] W.Z. Liu, Z.W. Luo, X.L. Hu, A.X. Lu, Effect of MgO addition on crystallization and properties of $\mathrm{Li}_{2} \mathrm{O}-\mathrm{ZnO}-\mathrm{SiO}_{2}$ glass-ceramics seals for copper, Thermochim. Acta, 584 (2014) 45-50.

[10] A.F. Nia, Thermal properties and crystallization of lithium-mica glass and glass-ceramics, Thermochim. Acta, 564 (2013) 1-6.

[11] O.A. Lafi, M.M.A. Omar, M.M.A. Imran, M.K. Abdullah, S.A. Al-Sakhel, Thermal characterization of $\operatorname{Se} 100-x \operatorname{Snx}(x=4,6$ and 8) chalcogenide glasses using differential scanning calorimeter, Thermochim. Acta, 560 (2013) 71-75.

[12] S. Pogatscher, D. Leutenegger, A. Hagmann, P.J. Uggowitzer, J.F. Loffler, Characterization of bulk metallic glasses via fast differential scanning calorimetry, Thermochim. Acta, 590 (2014) 84-90.

[13] R. Casasola, J.M. Pérez, M. Romero, Effect of fluorine content on glass stability and the crystallisation mechanism for glasses in the $\mathrm{SiO}_{2}-\mathrm{CaO}-\mathrm{K}_{2} \mathrm{O}-\mathrm{F}$ system, J. Non-Cryst. Solids 378 (2013) $25-33$.

[14] R. Casasola, J.M. Pérez, M. Romero, Glass forming ability and thermal stability of F-phlogopite based glasses, J. Therm. Anal. Calorim. in press, doi: 10.1007/s10973-015-4524-1.

[15] T.R. Marques, A.A. Aluisio, Influence of the heating rates on the correlation between glass-forming ability (GFA) and glass stability (GS) parameters, J. Non-Cryst. Solids 390 (2014) 70-76.

[16] A.M. Rodrigues, J.M.R. Mercury, V.S. Leal, A.A. Cabral, Isothermal and non-isothermal crystallization of a fresnoite glass, J. Non-Cryst. Solids 362 (2013) 114-119.

[17] A.A. Cabral, A.A.D. Cardoso, E.D. Zanotto, Glass-forming ability versus stability of silicate glasses. I. Experimental test, J. Non-Cryst. Solids 320 (2003) 1-8.

[18] R.L. Thakur, S. Thiagarajan, Studies in catalyzed crystallization of glasses: A DTA method, Cent. Glass. Ceram. Res. Inst. Bull 13 (1966) 33-45.

[19] D. Turnbull, Under what conditions can a glass be formed?, Contemporary Physics 10 (1969) 473488.

[20] I.W. Donald, B.L. Metclafe, L.A. Gerrard, S.K. Fong, The influence of $\mathrm{Ta}_{2} \mathrm{O}_{5}$ additions on the thermal properties and crystallization kinetics of a lithium zinc silicate glass, J. Non-Cryst. Solids 354 (2008) 301-310.

[21] M.C. Weinberg, An assessment of glass stability criteria, Phys. Chem. Glasses 35 (1994) 119-123. 
R. Casasola, J.M. Pérez, M. Romero, Devitrification behavior and preferred crystallization mechanism of glasses based on fluorrichterite $\left(\mathrm{Na}_{2} \mathrm{CaMg}_{5} \mathrm{Si}_{8} \mathrm{O}_{22} \mathrm{~F}_{2}\right)$ composition.

Thermochimica Acta 619 (2015) 32-40; doi:10.1016/j.tca.2015.09.014

[22] A. Hrubÿ, Evaluation of glass-forming tendency by means of DTA, Czech Phys. B. 22 (1972) 11871193.

[23] Z.P. Lu, C.T. Liu, A new glass-forming ability criterion for bulk metallic glasses, Acta Mater. 50 (2002) 3501-3512.

[24] Z.P. Lu, C.T. Liu, Glass Formation Criterion for Various Glass-Forming Systems, Phys. Rev. Lett. 91 (2003) 115505-115508.

[25] M.L.F. Nascimento, L.A. Souza, E.B. Ferreira, E. Zanotto, Can glass stability parameters infer glass forming ability?, J. Non-Cryst. Solids 351 (2005) 3296-3308.

[26] M.L.F. Nascimento, N.O. Dantas, Assessment of Glass-Forming Ability and the Effect of $\mathrm{La}_{2} \mathrm{O}_{3}$ on Crystallization Mechanism of Barium Lead Zinc Phosphate Glasses, Mat. Lett. 61 (2007) 912-916.

[27] C. Parmelee, C. Harman, Ceramic glazes, $3^{\text {rd }}$ edn., CBLS, Marietta, 1973.

[28] S. Likitvanichkul, W.C. Lacourse, Effect of fluorine content on crystallization of canasite glassceramics, J. Mat. Sci. 30 (1995) 6151-6155.

[29] P.F. James, M.H. Lewis, Glasses and Glass-Ceramics, Chapman and Hall, London, 1989.

[30] E.D. Zanotto, Isothermal and adiabatic nucleation in glass, J. Non-Cryst. Solids 89 (1987) 361-370.

[31] E.D. Zanotto, M.C. Weinberg, Trends in homogeneous crystal nucleation in oxide glasses, Phys. Chem. Glasses 30 (1989) 186-192.

[32] I.W. Donald, B.L. Metclafe, L.A. Gerrard, S.K. Fong, The influence of $\mathrm{Fe}_{2} \mathrm{O}_{3}$ and $\mathrm{B}_{2} \mathrm{O}_{3}$ additions on the thermal properties, crystallization kinetics and durability of a sodium aluminum phosphate glass $\mathrm{J}$. Non-Cryst. Solids, 352 (2006) 2993-3001.

[33]. A.F. Kozmidis-Petrovic, Theoretical analysis of relative changes of the Hruby, Weinberg, and LuLiu glass stability parameters with application on some oxide and chalcogenide glasses Thermochim. Acta, 499 (2010) 54-60. 